\title{
Rapid Processing of Net-Shape Thermoplastic Planar-Random Composite Preforms
}

\author{
S. T. Jespersen • F. Baudry • D. Schmäh • \\ M. D. Wakeman • V. Michaud • P. Blanchard • \\ R. E. Norris • J.-A. E. Månson
}

Received: 13 August 2008 / Accepted: 18 December 2008 /

Published online: 13 January 2009

(C) Springer Science + Business Media B.V. 2009

\begin{abstract}
A novel thermoplastic composite preforming and moulding process is investigated to target cost issues in textile composite processing associated with trim waste, and the limited mechanical properties of current bulk flow-moulding composites. The thermoplastic programmable powdered preforming process (TP-P4) uses commingled glass and polypropylene yarns, which are cut to length before air assisted deposition onto a vacuum screen, enabling local preform areal weight tailoring. The as-placed fibres are heat-set for improved handling before an optional preconsolidation stage. The preforms are then preheated and press formed to obtain the final part. The process stages are examined to optimize part quality and throughput versus processing parameters. A viable processing route is proposed with typical cycle times below $40 \mathrm{~s}$ (for a plate $0.5 \times 0.5 \mathrm{~m}^{2}$, weighing $2 \mathrm{~kg}$ ), enabling high production capacity from one line. The mechanical performance is shown to surpass that of $40 \mathrm{wt} . \%$ GMT and has properties equivalent to those of $40 \mathrm{wt} . \%$ GMTex at both $20^{\circ} \mathrm{C}$ and $80^{\circ} \mathrm{C}$.
\end{abstract}

S. T. Jespersen · F. Baudry $\cdot$ D. Schmäh $\cdot$ M. D. Wakeman • V. Michaud · J.-A. E. Månson $(\bowtie)$ Laboratoire de Technologie des Composites et Polymères (LTC),

École Polytechnique Fédérale de Lausanne (EPFL), CH-1015 Lausanne, Switzerland

e-mail: jan-anders.manson@epfl.ch

P. Blanchard

Ford Research and Innovation Center, Ford Motor Company, 2101 Village Road, Dearborn, MI 48124-2053, USA

R. E. Norris

Oak Ridge National Laboratory, US Department of Energy, P.O. Box 2008, Oak Ridge, TN 37831, USA

Present address:

F. Baudry

Rieter Automotive Heatshields AG, Sevelen, Switzerland

Present address:

D. Schmäh

Hydroptere, Lausanne, Switzerland

Present address:

M. D. Wakeman

DuPont de Nemours International S.A., Meyrin, Geneva, Switzerland 
Keywords Preforming $\cdot$ Net-shape $\cdot$ Thermoplastic composites $\cdot$ Stamp forming

\section{Introduction}

\subsection{The Original Programmable, Powdered Preforming Process}

This work examines a thermoplastic derivative of the $\mathrm{P} 4$ process (programmable powdered preforming process), here donated TP-P4, $[1,2]$. The original $\mathrm{P} 4$ process consists of a netshape preforming technique where glass fibre yarn is chopped and deposited with a powder binder (typically $5 \mathrm{wt} . \%$ ) onto a vacuum screen, Fig. 1 . This is performed using a chopper gun mounted on an industrial robot, see Fig. 1. In a subsequent heat set cycle a consolidation screen then compresses the fibres while hot air is forced through the preform, melting the powder binder. This generates semi-rigid preforms which are then injected in RTM and SRIM cycles using a variety of thermoset resin systems [3-5]. The P4 process targets waste issues associated with non crimp fabric (NCF) or textile materials. A carbon variant was also developed for higher performance requirements [6-8].

The P4 process, (also known as F3P), has been used in production for Aston Martin, where the supplier Sotira has produced over 34,000 parts per year over several applications $[9,10]$. It was also used by Meridian to make the optional Chevy Silverado SRIM box and tailgate inner panel [4]. Cycle times were approximately $3 \mathrm{~min}$ for this part with $10 \mathrm{~s}$ injection time for $17 \mathrm{~kg}$ fast curing Bayer 425 IMR urethane resin, though post-curing was necessary $[11,12]$. Although highly automated, the P4 system cycle time was, depending on preform size and weight, limited by the installed chopper rate $(<4 \mathrm{~kg} / \mathrm{min})$ and the subsequent liquid moulding cycle time, which is dominated by the cure of the resin system.

\subsection{The Novel TP-P4 Process}

The TP-P4 process examined here comprises the five key stages of: preforming, heatsetting, optional preconsolidation, preheating and the final non-isothermal press moulding process. This is shown schematically in Fig. 2. The first and second stages use similar equipment to the original $\mathrm{P} 4$ process, but the consolidation process changes from liquid infusion when using commingled yarns of glass and polypropylene (PP) fibres. The final moulding process hence differs, in that a non-isothermal press moulding operation is used to consolidate the preform, which is aided by the small matrix to fibre mass transfer distance in the commingled yarn and elimination of infusion and reticulation steps needed for RTM and SRIM processing [13, 14].
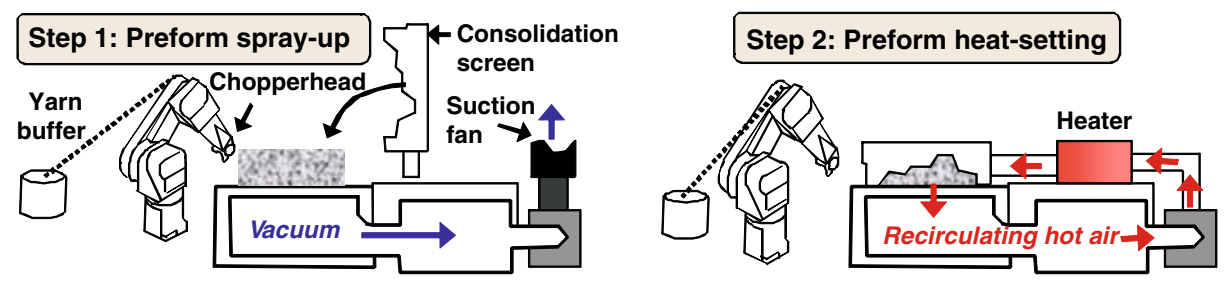

Fig. 1 Schematic of the preforming system with step 1 showing the deposition of fibres and step 2 the heatsetting of the preforms 


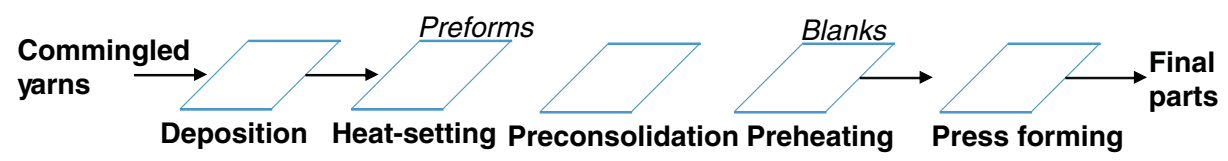

Fig. 2 Schematic of the stages in the TP-P4 process

\subsection{Objectives}

The specific objectives of this work were to investigate the practical feasibility of TP-P4 and to determine the rate limiting steps in the process and how these could be eliminated such that TP-P4 could be used at high manufacturing volumes, for example 200,000 units per year from one tool set. The work was performed using existing processing equipment and throughput has been limited by this; however, whenever possible, the results are generalised to other comparable processing systems.

Since deposition rate is a limitation in the original $\mathrm{P} 4$ process, the chopping process was specifically studied with the aim of understanding how the different yarn properties (a mix of GF and PP rather than plain GF) behaved in the chopper and how this affected throughput and fibre length distribution. The robot axis rate utilization could also be a limiting issue, and this was hence modelled for different chopping rates and areal weight requirements.

As early work showed that TP-P4 preforms required a stabilization stage following deposition, the heat setting stage was examined to determine the effect on the preform microstructure towards limiting the time required whilst giving suitable stability for subsequent handling and any transportation.

A future paper will examine the preconsolidation stage and final moulding stage in detail. The objectives here were to generally test if the preforms could be successfully preconsolidated, preheated and press-formed. Additionally, isothermally preconsolidated samples were tested to evaluate the mechanical performance for comparison with other material technologies such as glass mat thermoplastics (GMTs).

\section{Material and Experiments}

\subsection{Material}

The material was 1870 tex Twintex $60 \mathrm{wt} . \%$ glass/PP commingled yarn produced by OCV reinforcements. The linear weight of yarn from different Twintex rolls was measured and a $\sim 3 \%$ variation was found, compared with pure glass at $\sim 1 \%$ variation [15]. The weight per length was programmed into the deposition routine in order to limit part to part variations; $100 \times 609.6 \times 609.6 \mathrm{~mm}^{2}$ samples of $1,113 \mathrm{~g}$ on average were measured giving a $\pm 0.6 \%$.

\subsection{Void Analysis}

To study the TP-P4 void content quantitative void analysis was performed. An Olympus BX61 optical microscope equipped with a motorized $\mathrm{X}-\mathrm{Y}-\mathrm{Z}$ stage was used to capture multiple images, which were stitched together prior to image analysis. An example is shown in Fig. 3. The samples were mounted in Struers DuroFix-2 resin and polished. The micrographs were analyzed with AnalySIS ${ }^{\mathrm{TM}}$ software based upon binary segmentation where voids are darker than the fibers (white) and the surrounding matrix (gray), as shown 


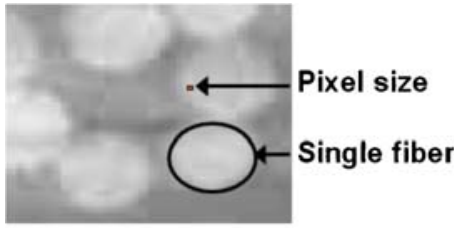

(a.)

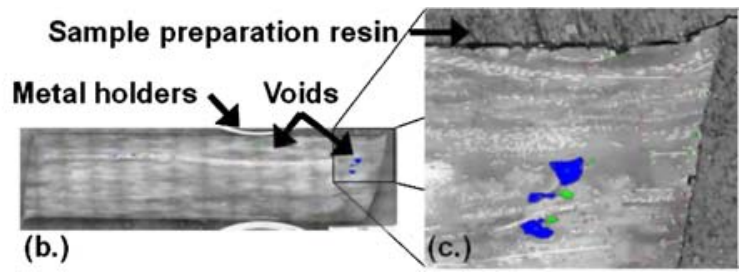

(b.)

Fig. 3 a Pixel resolution when determining void content. b Example of void analysis micrograph using stitched pictures. c Detail showing different void classes. Scale: fiber diameter is $\sim 19 \mu \mathrm{m}$

in Fig. 3b. The voids were categorized in different classes (based on the ferret diameter) to monitor changes in total void content, but also the evolution of void morphology, such as matrix based or intra bundle voids, as shown in Fig. 3c.

\section{Deposition Step}

\subsection{System Overview}

The deposition stage of the preforming system consisted of multiple (typically four) commingled yarns being fed through the robot handling system through a series of tubes and optional pre-tensioning system to the chopper head. It is one of the potentially limiting parts of the processing system for both cycle time and final mechanical performance.

The chopper head ( 40 kg) was mounted on a six-axis ABB IRB6400 industrial robot. The $60 \mathrm{~mm}$ diameter inlet rollers pull the fibres into the chopper head through an eyelet for minimum resistance. The fibres then pass through a $90^{\circ}$ tube before being chopped with a $\sim 95 \mathrm{~mm}$ diameter knife wheel with three carbon steel blades against a $\sim 64 \mathrm{~mm}$ diameter rubber roller, each with a separate driving motor. Fibre lengths can be varied continuously almost infinitely depending on the fibre throughput and chopper speed but are here varied from 25 to $75 \mathrm{~mm}$. To assist the fibres in reaching the deposition screen, 4 bar (adjustable) air pressure is applied through an air gun inside the chopper ejectors. The throat of the ejector nozzle is $12 \mathrm{~mm}$ and the end of the nozzle $18 \mathrm{~mm}$. The throughput speed of the chopper is matched with the robot accelerations and decelerations to fabricate preforms with low local areal weight variations measured from $76.4 \mathrm{~mm}$ diameter circular samples. A maximum variation of $\pm 3 \%$ was found; this is a slight improvement compared with the $\pm 5 \%$ to $7 \%$ found by Chavka et al. [1], possibly due to continuous system optimisation.

A series of investigations were made to determine how the original $\mathrm{P} 4$ process parameters needed to be adapted to suit the specific cutting characteristics of the commingled yarn. Our tests suggest a higher frequency of blade breakage with the commingled yarns which we attribute to the difficulty in completely severing the polypropylene, however, the difference in downtime intervals was not substantial. The deposition process was found to be limited by several other factors, including material feed constraints, and robot acceleration limitations, which are examined in the following sections.

\subsection{Chopping Throughput}

The efficiency of the complete deposition system is based on the maximum throughput the chopper head can deliver. This was examined chopping 25 and $75 \mathrm{~mm}$ long fibres using four rovings into an empty reservoir and comparing the set-point with the actual 
throughput. Two inlet systems were used; (1) the original inlet system with pre-tensioners, used to avoid fluctuations in the tension force in the tows, and (2) with the bypassing of the pre-tensioning weights.

At higher feed rates, the pre-tension weights were constantly pulled at the maximum stroke and hindered throughput. Since this did not happen with pure glass fibres it is believed that the PP fibres increase friction in the system, in particular the inlet tubes. As a consequence it was decided to by-pass the pre-tension mechanism and feed the Twintex tows directly to the chopper head. Without the pre-tensioning weights, as observed in Fig. 4, the actual/set throughput ratio remained linear in all tested cases. Under these conditions the maximum chopping rate for $75 \mathrm{~mm}$ fibres was nominally $4,200 \mathrm{~g} / \mathrm{min}$ due to the rubber roller being worn off, possibly due to different velocity of the knife and rubber wheels. Note also that the experiment for $25 \mathrm{~mm}$ fibres was stopped at 3,200 g/min and that this was not the maximum achievable chopping rate. When designing the inlet system, special care should thus be given to the fibre guiding system.

\subsubsection{Alternative Chopper Solution}

An alternative chopper head (Wolfangel Gmbh, Germany) was tested to alleviate jamming and the low throughput of the current head; however, this head was not used to make material for other experiments. This chopper used only one driving motor to avoid speed difference between rubber roller and knife wheel. This chopper also made it possible to change between two distinct fibre lengths during runtime, by using a two-setting knife wheel, each length pre-adjustable between 3 and $100 \mathrm{~mm}$. To test the robustness of the head, a large amount of roving was continuously chopped, and no jamming occurred. The throughput of the commercially available system was $6 \mathrm{~kg} / \mathrm{min}$ with three roving ends and up to $12 \mathrm{~kg} / \mathrm{min}$ with six roving ends. To meet the anticipated annual volume of 200,000 parts per year, deposition rates of $7.7 \mathrm{~kg} / \mathrm{min}$ would be needed for a $1-\mathrm{m}^{2}$ square part of mass $5 \mathrm{~kg}$ for a typical two-shift working pattern (incl. $2 \times 5 \mathrm{~s}$ transfer times).

\subsection{Chopped Fibre Length Distribution}

One of the advantages of the TP-P4 process is the ability to change the chopping length during runtime. This allows the production of preforms with a constant or changing fibre length depending on the local mechanical requirements and rib features (flow required) in the component. The dependence of fibre length on mechanical properties is examined separately in Section 8, and fibre flow for this system will be examined in a separate paper. However, in order to get improved user control of this feature, the fibre length distribution

Fig. 4 Comparison between set and actual throughput for 25 and $75 \mathrm{~mm}$ long fibres with and without pre-tension

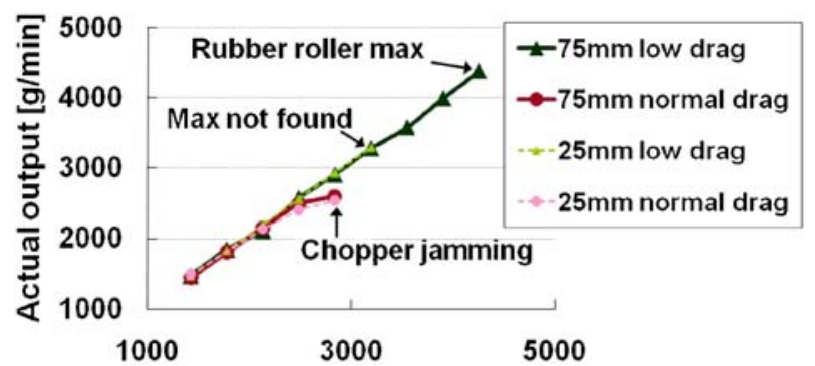

Setpoint $[\mathrm{g} / \mathrm{min}]$ 
must be constrained around the desired length. To measure this distribution, the robot and chopper head was left stationary and the feed rate was adjusted for each fibre length to have the same rotational cutter speed and the fibre lengths measured with a calliper, with a precision of $\pm 0.01 \mathrm{~mm}$, Table 1 . The bypassing of an optional pre-tensioner was also tested.

Figure 5 presents the statistical fibre length distribution, counting the proportion of fibre lengths belonging to $5 \mathrm{~mm}$ intervals. At a target fibre length of $50 \mathrm{~mm}$, the average fibre length distribution shows two peaks at 36-40 and 56-60 mm. A significant number of pairs at $\sim 35$ and $\sim 60 \mathrm{~mm}$ were found together, indicating that they were cut just after one another. Alternating slightly longer and slightly shorter fibres with twice the target length could indicate a stick/slip problem in the chopper head or elsewhere in the line. Since this issue was not found when a pre-tensioner was used, it is considered that too little slack restricts the maximum throughput whereas too much can scatter the fibre length distribution. Note that the same issue was found for the $25 \mathrm{~mm}$ long fibres (peaks at 2125 and $31-35 \mathrm{~mm}$ ) but not with the $75 \mathrm{~mm}$ fibres. However, removing the pre-tensioner suppressed significantly long 'tails' in all distributions and hence this set-up was used for the remainder of the preforms.

\subsection{Deposition Cycle Simulation}

An analytical model has been developed to generate reliable cycle time estimates accounting for the established chopper limitations, robot accelerations, spray-up parameters and preform geometry. The derived expression generally works with six axis robots, however, six system specific parameters are used to model the ABB IRB6400 robot applied in the current system. The expression is based upon preforming of a single spray-up layer, but the approach could easily be extended to include multiple layers. Minimum two passes are typically used to decrease local areal density variations. It is assumed that the chopper can change speed to match robot accelerations and decelerations. With constant chopper rate it was observed that the preform boarders were significantly thicker. Only three parameters are needed; the maximum chopper output, the area weight required and the spray-up pattern. The maximum possible and allowable robot speed, $V_{\text {rob_max }}$, must first be found:

$$
V_{\text {rob_max }}=\frac{\text { Max chopper output }}{\text { Areal weight } \times \text { Width }} .
$$

For the spray-up pattern the length $(L)$ and bandwidth $(W)$ of each movement must be known. The bandwidth between passes will in practice be determined by chopper design and tows used, together with an experimental verification of required overlap and chopper to screen distance versus local areal density variations. The screen/chopper distance,

Table 1 Average fibre length distribution measurements

\begin{tabular}{|c|c|c|c|c|c|c|c|}
\hline \multirow[b]{2}{*}{$\begin{array}{l}\text { Set-fibre } \\
\text { length }[\mathrm{mm}]\end{array}$} & \multirow[b]{2}{*}{ Output $[\mathrm{g} / \mathrm{min}]$} & \multicolumn{3}{|c|}{ No pre-tension } & \multicolumn{3}{|c|}{ With pre-tension } \\
\hline & & $\begin{array}{l}\text { Average } \\
\text { length }[\mathrm{mm}]\end{array}$ & $\mathrm{SD}[\mathrm{mm}]$ & Stat. sample & $\begin{array}{l}\text { Average } \\
\text { length }[\mathrm{mm}]\end{array}$ & $\mathrm{SD}[\mathrm{mm}]$ & $\begin{array}{l}\text { Stat. } \\
\text { sample }\end{array}$ \\
\hline 25 & 1,418 & 28.6 & 8.6 & 248 & 29.0 & 9.0 & 218 \\
\hline 50 & 2,836 & 50.0 & 11.4 & 259 & 46.1 & 16.0 & 220 \\
\hline 75 & 4,254 & 74.5 & 9.9 & 204 & 56.8 & 17.0 & 235 \\
\hline
\end{tabular}




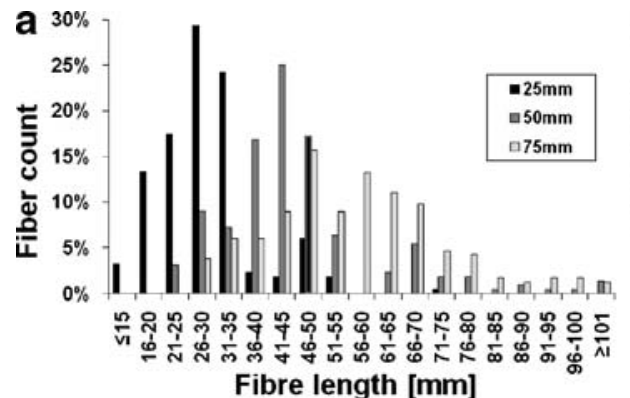

Fibre length [mm]

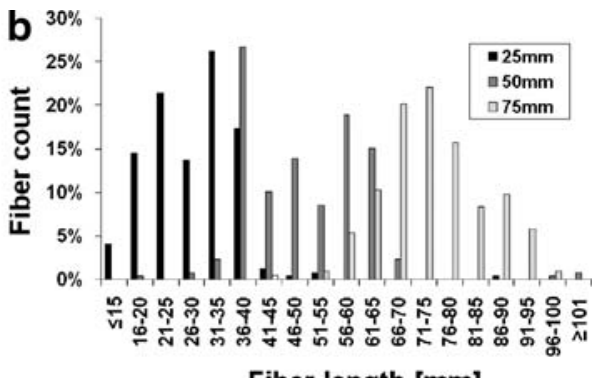

Fiber length [mm]

Fig. 5 Fibre length distribution a with and $\mathbf{b}$ without pre-tension weights

bandwidth and overlap relationship for optimum properties had, for the used deposition equipment, been carried out prior to this work and already part of the deposition software. With this knowledge the model can be used to optimise the chopper design and tows used for a specific application. For rectangular preform shapes this will be a number of equivalent movements, simplifying calculations. This is schematically shown in Fig. 6, where four U-shaped passes and identical start and stop (time wise) movements are used. For complex part shapes, the calculations can be performed in a spreadsheet using the same equation and method as for single passes.

The cycle times were calculated using Eqs. 2 and 3. The parameters A to F were determined from 216 simulations performed in RobCAD. This software has an embedded controller for the specific robot concerned, including modelling of the deposition head weight of $41 \mathrm{~kg}$, moments of inertia $\left(1.29 ; 1.88 ; 1.13 \mathrm{~kg} \cdot \mathrm{m}^{2}\right)$ and centre of gravity $(370 ; 25$; $255 \mathrm{~mm})$. The time for one U-turn is calculated as:

$$
\frac{L+W}{V_{\mathrm{rob}}}+V_{\mathrm{rob}}(C \times W+D)+E \times W+F
$$

where $C=6.6 \mathrm{E}-7, D=1.84 \mathrm{E}-4, E=-1.45 \mathrm{E}-3$ and $F=-0.064$. Each start and end turn is calculated as:

$$
\left(\frac{L}{V_{\mathrm{rob}}}+A \times V_{\mathrm{rob}}+B\right) / 2
$$

where $A=7.32 \mathrm{E}-5$, and $B=0.411$.

In order to reach a homogeneous areal weight, the model takes into account robot accelerations and decelerations. As a result, the actual chopper output numbers are lower than the maximum outputs, Fig. 7. For a $100-\mathrm{mm}$ bandwidth, $500 \times 500 \mathrm{~mm}^{2}$ part dimensions, and $2 \mathrm{~kg}$ preform weight this translates into a 41 -s cycle time at $70 \mathrm{~mm} / \mathrm{s}$ robot speed and $4.2 \mathrm{~kg} / \mathrm{min}$ required (2.9/min average) chopper output, which is the largest chopper speed achieved with the current chopper. If two passes are needed to obtain sufficient area coverage the robot can move with $158 \mathrm{~mm} / \mathrm{s}$ for a cycle time of $36 \mathrm{~s}$ giving

Fig. 6 Schematic robot movements. Bandwidth, $W$, and length, $L$, of passes are indicated

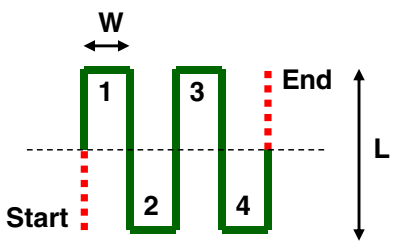


Fig. 7 Deposition example for $100 \mathrm{~mm}$ bandwidth, $500 \times$

$500 \mathrm{~mm}^{2}$ part dimensions and

$2 \mathrm{~kg}$ preform weight

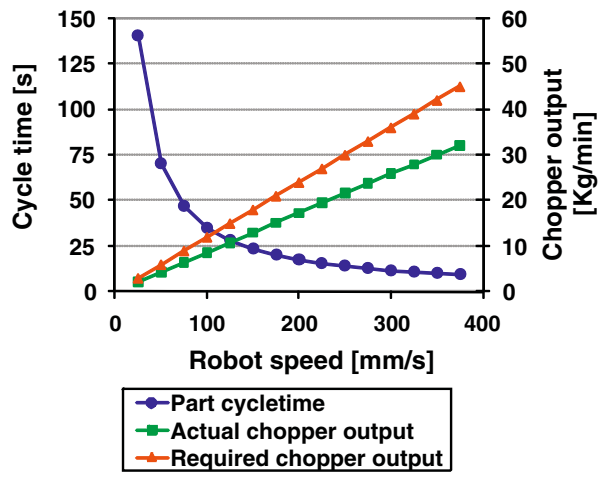

an actual chopper rate of $3.3 \mathrm{~kg} / \mathrm{min}$. For heavier parts, a chopper with higher throughput is required, such as the Wolfangel chopper, to achieve low cycle times. The cycle time of $36 \mathrm{~s}$ corresponds approximately (incl. $2 \times 5 \mathrm{~s}$ transfer times) to 262,000 parts per year anticipated production capacity for a typical two-shift working pattern. Even though this calculation is specific to the model of robot used in the present work, the results can be used as indications for the potential cycle time that can be achieved in an industrial environment.

\section{Heat-Setting Step}

The heat setting stage is required such that the deposited dry commingled yarn is partially consolidated to a state that enables subsequent handling. During the stabilization stage, hot air is blown through the preform to melt the polypropylene matrix while applying a constant compaction force of $\sim 0.3$ bar on the preform.

During the heat-setting period, the air temperature was increased above the preform polymer melt temperature $\left(T_{\mathrm{m}}\right)$, and later cooled to below $T_{\mathrm{m}}$. The temperature just below the preform depends on the preform thickness and hence the flow through the preform, as shown in Fig. 8. Increased air temperature increased preform upper surface heating rates. All tests were carried out with $25 \mathrm{~mm}$ fibre length samples. Adequate stabilisation for transportation required an approximate minimum heat setting time at $310^{\circ} \mathrm{C}$ of 5,15 , and $25 \mathrm{~s}$ for 2, 3 and $4 \mathrm{~mm}$ thick (as pressed) preforms respectively. The 2, 3 and $4 \mathrm{~mm}$ (as

Fig. 8 Heat-setting temperature scans measured above and below the preforms for 2, 3 and $4 \mathrm{~mm}$ thick (as pressed) preforms at $270^{\circ} \mathrm{C}$ air temperature for specific 'hold' times

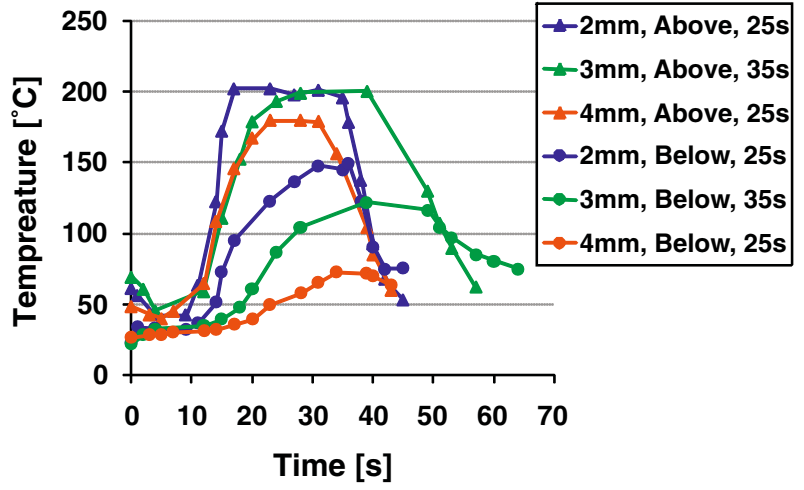


pressed) thicknesses corresponds to $3,4.5$ and $6 \mathrm{~kg} / \mathrm{m}^{2}$ areal weight respectively, but after heat setting the thicknesses are approximately three times larger.

In a future set-up, the heat-setting stage can be carried out in parallel to the deposition of the following preform. With heat-setting cycle times lower than typical deposition times there is no need for parallel equipment, simplifying high volume production.

\section{Preconsolidation}

As mentioned previously, a future paper will examine the preconsolidation stage in more detail. This is considered an optional step, which would ideally be eliminated to reduce cost. In this early work, the preconsolidation step was used in order to obtain full part quality after press forming. Isothermal preconsolidation was examined since it corresponds to the current industrial practice of using double press systems, for example with GMT and prepreg materials, to ensure well impregnated preforms prior to preheating and press forming.

The TP-P4 preforms were preconsolidated in a hydraulic $200 \mathrm{kN}$ Tempcraft laboratory press. The TP-P4 material was placed in a $457 \times 457-\mathrm{mm}^{2}$ flat shear edge tool at $204^{\circ} \mathrm{C}$ and pressed at $\sim 10$ bar for $60 \mathrm{~s}$, followed by a cooling phase at $\sim 10$ bar constant pressure for $45 \mathrm{~min}$ to $90^{\circ} \mathrm{C}$. Degradation due to extended time at temperature was not observed. The isothermal preconsolidation route gave void contents below $0.1 \%$ (Section 2), and good mechanical properties after preconsolidation, as discussed in Section 8. Such an operation would be commercially scaled using a double belt press, but this would make local thickness changes unfeasible. Another solution could be an induction heating system such as the ROC tool Cage system (Azdel). This system has shown cycle times for a $1-\mathrm{m}^{2}$ thermoplastic car bonnet of less than 4 min and would allow for local thickness variations [16].

\section{Preheating}

The final moulding process follows the conventional routes of either non-isothermal stamping (no shear edge in tool) or compression moulding (with shear edge) using a preheat-oven to bring the preform above the melt temperature. With the final conversion process for TP-P4 following this approach, it is necessary to preheat the preforms above the melting point of polypropylene at $\sim 165^{\circ} \mathrm{C}$, without inducing degradation before stamping or press forming.

Heating experiments were conducted using a Krelus AG medium wave (2.6-9.6 $\mu \mathrm{m})$ fast response infrared (IR) oven (ON 8 s/OFF $2 \mathrm{~s}$ ) at the Ford research and innovation centre). This uses six heaters per bank (12 total) each with a 0 - to $2-\mathrm{kW}$ capacity and $0.06 \mathrm{~m}^{2}$ area individually controllable for uniform heating. The material surface temperature was measured and controlled using optical pyrometers mounted in air cooled sleeves perpendicular to the material (one per heater bank). Readings from thermocouples placed at the surface were compared to the pyrometer readings and a good correlation between the two was observed, enabling use of pyrometer readings for temperature control.

\subsection{Lofting}

During the preheat cycle the polypropylene matrix in the preform melts which releases trapped elastic forces in the glass structure resulting in a lofting effect, which is well known in GMT materials [17-19]. In Fig. 9 the microstructure of preheated TP-P4 is compared to 

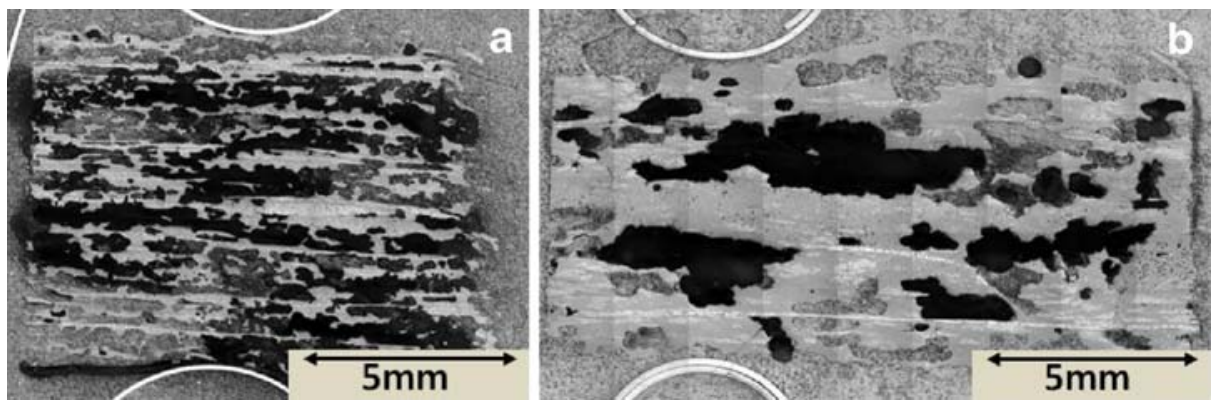

Fig. 9 Microstructure after $202^{\circ} \mathrm{C}$ preheating of a 60 wt. $\%$ TP-P4 and b 30 wt. $\%$ GMT

that of GMT. The TP-P4 material is distributed over the entire thickness. For GMT, the microstructure is different in that the needling holds the material together in larger bundles giving larger structural stability. The larger agglomeration size also makes it easier to preheat the GMT material than preconsolidated TP-P4 material even though it contains less fibres. Increased filamentisation has been reported to give more distributed and out of plane fibres for the original P4 process [20]; if a similar behaviour was found for the TP-P4 technology it could potentially be used to change the lofting behaviour.

\subsubsection{Results}

The IR oven was used to heat-up $3 \mathrm{~mm}$ thick isothermally preconsolidated samples at three different oven temperatures, Fig. 10. The pyrometer readout surface temperature reached the oven set-temperature rapidly (not shown), whereas it took $200 \mathrm{~s}$ to reach $200^{\circ} \mathrm{C}$ in the material centre (measured by thermocouple) at an oven temperature of $202^{\circ} \mathrm{C}$, causing no visible degradation. The process limit is reached for the sample heated at $225^{\circ} \mathrm{C}$ for $218 \mathrm{~s}$, where the centre temperature is seen to increase beyond $225^{\circ} \mathrm{C}$ due to an exothermic reaction caused by degradation.

\section{Non-Isothermal Stamp Forming}

This paper examines a stamp forming process [21] to consolidate the preheated TP-P4 preforms; a future paper will examine consolidation in a shear edge tool at higher moulding pressures. The rationale for stamp-forming TP-P4 material is that increased shape drawing can be obtained compared with the drapability of Twintex in textile form, and local thickness variations can be accommodated. Such stamped inserts could also be used as

Fig. 10 Comparison of the centre and oven set-temperature for preheating of $3 \mathrm{~mm}$ isothermally consolidated 60 wt. $\%$ TP-P4

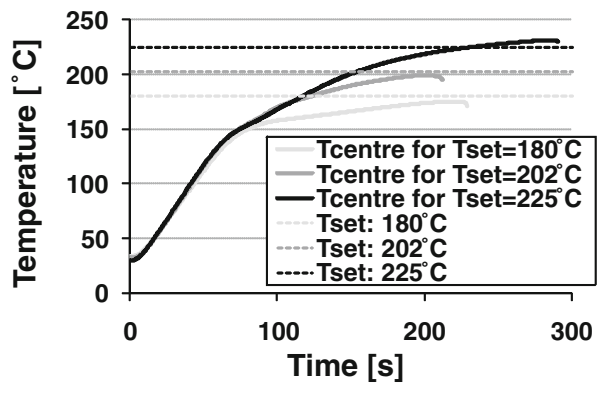


local structural inserts for over-moulding with for example, D-LFT or GMT. The objectives were to determine the effect of consolidation pressure and press parameters on the final void content and mechanical properties after press forming.

\subsection{Equipment}

A fast acting hydraulic stamping press with accumulator at the Ford research and innovation centre was used, with a maximum compression speed of $166 \mathrm{~mm} / \mathrm{s}$ and $<1 \mathrm{~s}$ pressure build-up times. The previously described infrared preheating stage was connected to the press via a linear panel transfer system. An oil heated double dome tool [20] of $\sim 250 \times 500 \mathrm{~mm}^{2}$ and a 3-mm cavity separation, without shear edge, was used for all stamping trials. A data acquisition system was used to record the moulding cycle pressure history from three transducers in $0.5 \mathrm{~s}$ intervals.

\subsection{Stamp Forming of Isothermally Preconsolidated TP-P4}

A design of experiments (DOE) approach using a three factor three level partial factorial array was used to select the optimum process conditions, considering: Preheat temperature, tool temperature, and pressure, as shown in Table 2. Several other factors were held constant such as the time at pressure at $30 \mathrm{~s}$, clamping of the preform during press forming, and transfer time, here approximately $2 \mathrm{~s}$. Thickness measurements were performed on all stampings to be used as response parameters and an average thickness of $2.70 \mathrm{~mm}$ was found. An open tool, typically used for fabric stamping, was used to examine the forming process for shell structures.

\subsubsection{Thickness Response}

The relation between the final stamped part thickness and varying pressure and preheat temperature is given in Fig. 11. Preheat temperature and pressure were the significant parameters at $90 \%$ confidence with $30 \%$ and $27 \%$ contributions respectively. A larger pressure and preheat temperature resulted in thinner samples; as a shear edge tool was not used, material effectively flowed out, and the final parts had varying areal density. The material flowed better at higher temperature since the viscosity of the matrix is decreased. The fact that bulk flow of the TP-P4 material occurred is highly encouraging because this will allow for locally varying cavity thicknesses (larger than for fabrics) while giving even consolidation. Based upon these results, further future work will examine the use of shear edge tools to give net shaped parts with thickness variations and also limit trimming of stampings.

Table 2 Processing parameters studied

\begin{tabular}{lrrr}
\hline & Low & Middle & High \\
\hline Preheat temperature $\left[{ }^{\circ} \mathrm{C}\right]$ & 180 & 190 & 200 \\
Tool temperature $\left[{ }^{\circ} \mathrm{C}\right]$ & 40 & 60 & 80 \\
Pressure $[$ bar $]$ & 10 & 20 & 30 \\
\hline
\end{tabular}


Fig. 11 DOE results for stamped thickness as a function of applied pressure and preheat temperature. Tool temperature was constant at $60^{\circ} \mathrm{C}$

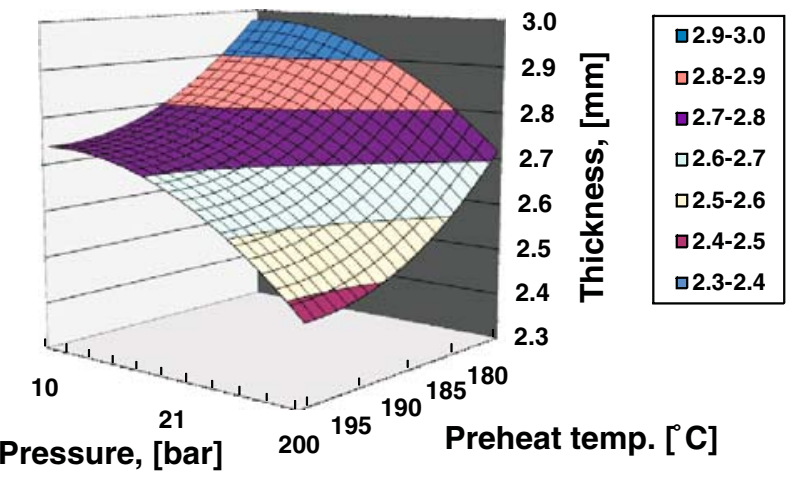

\subsubsection{Void Analysis}

Void analysis on a formed part, manufactured using the middle level parameters (except for temperature), Fig. 12, showed that void content was strongly dependent on position (Section 2). The results are almost symmetric, which indicates representative values. On the edge (positions 3 and 5) the void content is reduced $(0.04 \%$ and $0.21 \%)$, both for small intra bundle voids as well as larger matrix based porosity, whereas most other positions display larger void contents (up to $12.3 \%$ in position 8 ). This is caused by drawing of the material into the cavity. Most pressure is applied to the border where the panel is not drawn

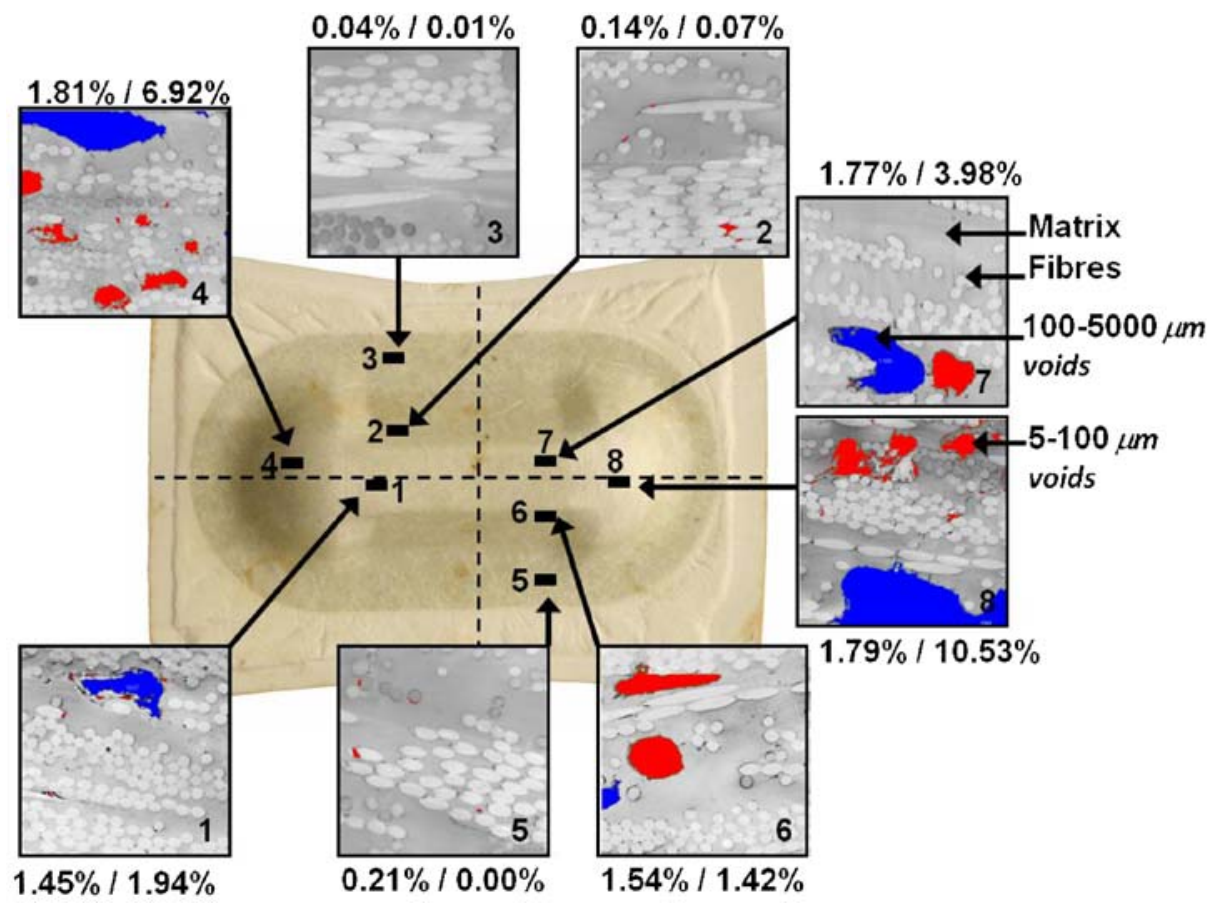

Fig. 12 Void mapping on sample preheated to $180^{\circ} \mathrm{C}$ and stamped at 20 bar and $60^{\circ} \mathrm{C}$ tool temperature. Results are split in two void classes: 5-100 $\mu \mathrm{m}$ (bright)/100-5,000 $\mu \mathrm{m}$ (dark). Micrograph close-ups are taken from representative areas of the samples. Magnification: fibre diameter is $\sim 19 \mu \mathrm{m}$ 
and therefore more material remains. In the drawn central areas a higher void content is observed since the cavity spacing is determined by the borders. Hence, the current mould is not ideally designed for the TP-P4 material, but rather for fabric materials which tend to drape rather than stretch into the cavity.

For simple geometries a tool temperature of $60^{\circ} \mathrm{C}$, a pressure of 30 bar, and $200^{\circ} \mathrm{C}$ preheating temperature is recommended. The equipment requirements for more complex geometries demand a more rigorous examination.

\section{Mechanical Properties}

TP-P4 $3 \mathrm{~mm}$ isothermally preconsolidated material was tested with tensile (ASTM D3039), compression (ASTM D3410-B), shear (ASTM D7078), and impact (ASTM D3763) measurement methods, as shown in Table 3. The effect of fibre length was minimal except for impact properties, which improved by $32 \%$ by increasing the length from 25 to $75 \mathrm{~mm}$. The tensile properties corresponds well with the result of the shear lag model [22] combined with the rule of mixture $[23,24]$ for planar random material with the standard orientation factor of $0.375[24,25]$. Using a modulus for fibre and matrix of 72 and $1.5 \mathrm{GPa}$ respectively, the resulting modulus of the composite is $10.1 \mathrm{GPa}$. This is calculated as:

$$
E_{\mathrm{c}}=\eta_{\theta} \eta_{1} E_{\mathrm{f}} V_{\mathrm{f}}+E_{\mathrm{m}}\left(1-V_{\mathrm{f}}\right)
$$

where $E_{\mathrm{c}}, E_{\mathrm{f}}$ and $E_{\mathrm{m}}$ is the modulus of the composite, fibres and matrix respectively. $V_{\mathrm{f}}$ is the fibre volume fraction. $\eta_{\theta}$ is the orientation factor. $\eta_{1}$ is an efficiency factor relating to the fibre length; here the value 1 is used since the fibre length for all the examined materials is longer than the critical length required for complete stress transfer between fibre and matrix [24-26].

\subsection{Comparison with Competing Materials}

Four different materials were chosen for comparison with the TP-P4 material, here listed with an explanation of the material codes:

- Quadrant GMT D100 F40; A 40-wt.\% GF/PP high flow, high area weight Glass Mat Thermoplastic (GMT).

- Quadrant GMTex X112 F40 4/1; A 40-wt.\% GF/PP textile reinforced GMT. The 4/1 weave (four times the amount of fibres in the $0^{\circ}$ direction) is on the outer layers. It has improved affinity to adhesives.

Table 3 Isothermally consolidated TP-P4 material properties versus fibre length

\begin{tabular}{llll}
\hline & 60 wt.\% GF, 25 mm & 60 wt.\% GF, 50 mm & 60 wt.\% GF, 75 mm \\
\hline Tensile modulus [GPa] & $9.9(1.1) / 8(1)$ & $10(1.5) / 8(0.7)$ & $10.2(1.2) / 9.4(1.8)$ \\
Ult. tensile strength [MPa] & $170(26) / 124(14)$ & $162(15) / 124(11)$ & $162(27) / 133(21)$ \\
Compressive modulus [GPa] & $10.7(0.9) / 7.9(1)$ & $9.3(1.2) / 7.6(0.9)$ & $9.7(1.3) / 7.3(1.2)$ \\
Ult. compressive strength [MPa] & $126(6) / 60(7)$ & $119(8) / 57(3)$ & $111(12) / 52(4)$ \\
Shear modulus [GPa] & $3.61(0.1) / 2.13(0.18)$ & $3.62(0.23) / 2.34(0.1)$ & $3.59(0.53) / 2.60(0.2)$ \\
Shear strength [MPa] & $82.1(15.1) / 48.3(3.9)$ & $92.7(9.7) / 38.8(3.6)$ & $83.9(5.9) / 44.1(3.1)$ \\
Impact total energy/area $\left[\mathrm{kJ} / \mathrm{m}^{2}\right]$ & $141(15)$ & $172(44)$ & $186(13)$ \\
\hline
\end{tabular}

The samples have been tested at $20 / 80^{\circ} \mathrm{C}$, with exception of the impact energy, which was only measured at $20^{\circ} \mathrm{C}$. The standard deviations are shown in parentheses 
- Quadrant GMTex X103 F60 4/1; A 60-wt.\% GF/PP textile reinforced GMT. The 4/1 weave is present both in the centre and outer layers.

- Vetrotex Twintex TPP 60 935BF; Consolidated plate based on pure Twintex GF/PP commingled yarns fabric. The base material is the same as used for the planar random TP-P4 material.

For the benchmark materials, shear tests were carried out with the same set-up, coupon geometries and standard (ASTM D7078) as the TP-P4 material. The tensile tests (ISO 527-4) and compression tests (ASTM D695) were either carried out in-house, or the values were supplied by the producer, and hence measured using a different set-up, but using the same standards, except for the Twintex compression data (here ISO8515 was used). The impact test for $40 \mathrm{wt} . \%$ GMTex 4/1 was performed with the same setup, coupon geometry and standard (ASTM D3763) as the TP-P4, but for the 60 wt.\% GMTex 4/1 and the 60 wt.\% Twintex another standard was used (ISO 179).

The TP-P4 mechanical properties were compared with those of Twintex fabric, GMT and GMTex materials, see Table 4. The 40 wt.\% moulded GMT properties were approximately $2 / 3$ that of TP-P4, for both temperatures, due to the lower fibre content. Matching the tensile properties of GMT with Eq. 4 generates an orientation factor of 0.26 , indicating a larger amount of out-of-plane fibres than for the TP-P4 material. Indeed, the

Table 4 Mechanical properties, tested at $20 / 80^{\circ} \mathrm{C}$ with the standard deviation in brackets

\begin{tabular}{|c|c|c|c|c|}
\hline & GMT & GMTex 4/1 & GMTex 4/1 & Twintex 4/1 \\
\hline Glass content [wt.\%] & 40 & 40 & 60 & 60 \\
\hline $\begin{array}{l}\text { Tensile modulus } 0^{\circ} \\
{[\mathrm{GPa}]}\end{array}$ & $4.7 / 4.1^{\mathrm{a}}$ & $8.8 / 8.1^{\mathrm{a}}$ & $20.1 / 19.5^{\mathrm{a}}$ & $20.7 / 18.1^{\mathrm{a}}$ \\
\hline $\begin{array}{l}\text { Tensile modulus } 90^{\circ} \\
{[\mathrm{GPa}]}\end{array}$ & Same as $0^{\circ}$ & $5.2 / 3.7^{\mathrm{a}}$ & $7.4 / 5.4^{\mathrm{a}}$ & $7.3 / 5.2^{\mathrm{a}}$ \\
\hline $\begin{array}{l}\text { Ult. tensile strength } \\
0^{\circ}[\mathrm{MPa}]\end{array}$ & $65 / 48^{\mathrm{a}}$ & $210 / 150^{\mathrm{a}}$ & $417 / 271^{\mathrm{a}}$ & $453 / 387^{\mathrm{a}}$ \\
\hline $\begin{array}{l}\text { Ult. tensile strength } \\
90^{\circ}[\mathrm{MPa}]\end{array}$ & Same as $0^{\circ}$ & $95 / 72^{a}$ & $120 / 95^{\mathrm{a}}$ & $152 / 131^{\mathrm{a}}$ \\
\hline $\begin{array}{l}\text { Compressive modulus } \\
0^{\circ}[\mathrm{GPa}]\end{array}$ & $6.3(0.8) / 4.9(0.3)$ & $10.9(0.9) / 9.8(1.6)$ & $22.6(1.3) / 15.7(2.0)$ & $8.5 / 4.6^{\mathrm{a}}$ \\
\hline $\begin{array}{l}\text { Compressive modulus } \\
90^{\circ}[\mathrm{GPa}]\end{array}$ & Same as $0^{\circ}$ & $6.9(0.6) / 5.6(0.7)$ & $6.9(0.7) / 5.7(0.6)$ & $5.1 / 3.9^{\mathrm{a}}$ \\
\hline $\begin{array}{l}\text { Ult. compressive strength } \\
0^{\circ}[\mathrm{MPa}]\end{array}$ & 71 (Na.)/39 (2) & 125 (Na.)/73 (4) & $181(\mathrm{Na}.) / 112(29)$ & $92 / 39^{a}$ \\
\hline $\begin{array}{l}\text { Ult. compressive strength } \\
90^{\circ}[\mathrm{MPa}]\end{array}$ & Same as $0^{\circ}$ & $82(\mathrm{Na}.) / 43(2)$ & $76(\mathrm{Na}.) / 41(3)$ & $66 / 30^{\mathrm{a}}$ \\
\hline $\begin{array}{l}\text { Shear modulus } G_{12} / G_{21} \\
0^{\circ}[\mathrm{GPa}]\end{array}$ & $2.2(0.0) / 1.9(0.2)$ & $1.6(\mathrm{Na}.) / 1.3(0.0)$ & $1.2(0.1) / 1.1(0.1)$ & $1.1(0.0) / 0.6(0.0)$ \\
\hline $\begin{array}{l}\text { Shear modulus } G_{12} / G_{21} \\
90^{\circ}[\mathrm{GPa}]\end{array}$ & Same as $0^{\circ}$ & $1.4(0.1) / 1.2(0)$ & $1.2(0.0) / 1.0(0.1)$ & $1.0(0.0) / 0.5(0.0)$ \\
\hline $\begin{array}{l}\text { Shear strength } \sigma_{12} / \sigma_{21} \\
0^{\circ}[\mathrm{MPa}]\end{array}$ & $56(5) / 31(2)$ & $63(7) / 37(2)$ & $43(5) / 24(4)$ & $43(4) / 18(3)$ \\
\hline $\begin{array}{l}\text { Shear strength } \sigma_{12} / \sigma_{21} \\
90^{\circ}[\mathrm{MPa}]\end{array}$ & Same as $0^{\circ}$ & $62(3) / 38(4)$ & $37(4) / 21(4)$ & $39(2) / 18(1)$ \\
\hline $\begin{array}{l}\text { Impact energy/area } \\
{\left[\mathrm{kJ} / \mathrm{m}^{2}\right] 0^{\circ} \text { and } 90^{\circ}}\end{array}$ & $\mathrm{Na}$. & $64(15)$ & 300 and $130^{\mathrm{a}}$ & 330 and $90^{\mathrm{a}}$ \\
\hline
\end{tabular}

\footnotetext{
${ }^{a}$ Values that have been supplied by the producer with no standard deviation.
} 
presence of out-of-plane fibres in the needled GMT mats is known [27], but compression moulding tends to reduce this effect [26]. The TP-P4 is comparable with $40 \mathrm{wt} . \%$ GMTex, and even exceeds them for tensile modulus and shear. Nevertheless, the $60 \mathrm{wt} . \%$ GMTex fabric variants showed higher tensile properties. The properties of both $60 \mathrm{wt} . \% 4 / 1$ weaves can be predicted (here done within $3 \%$ on average) by a simple rules of mixtures model [23] using a modulus for fibre and matrix of 72 and $1.5 \mathrm{GPa}$ respectively which gives 21.3 / $7.0 \mathrm{GPa}$ in $0 / 90^{\circ}$ directions. Taking the average of the $0^{\circ}$ and $90^{\circ}$ values at $20^{\circ} \mathrm{C}$ for $60 \mathrm{wt} . \%$ GMTex, the TP-P4 fares well with $72 \%$ of the tensile and compression modulus, $63 \%$ of the tensile strength and $98 \%$ of the compressive strength. At $80^{\circ} \mathrm{C}$, the difference becomes more pronounced. Finally, the $60 \mathrm{wt} . \%$ Twintex fabric has similar tensile properties to the equivalent 60 wt.\% GMTex, but lower compression properties, which are surpassed by TP-P4.

\section{Conclusions}

A process has been developed to produce thermoplastic composite materials with adjustable length in-plane randomly oriented fibres. The key processing steps were studied to relate processing conditions to part quality and determine optimum levels and process limitations in particular with respect to cycle times.

- Yarn deposition time has been modelled with a combination of chopper limitations and robot simulations. For a typical $2 \mathrm{~kg}, 500 \times 500 \mathrm{~mm}^{2}$ part, a cycle time of $\sim 36 \mathrm{~s}$ was needed. Means to reach even smaller cycle times have been shown using a new chopper. However, even the highest throughput speeds may not be sufficient to meet cycle time requirements if the part size and mass are too large. In that case it will be unavoidable to use parallel machines even when this adds to the required investment. Parallel machines are possible; for example four deposition robots were used by Meridian to produce glass P4 preforms for the Chevy Silverado optional SRIM box and tailgate inner panel [4].

- The heat-setting time was established to be at least 5, 15 and $25 \mathrm{~s}$ for 2, 3 and $4 \mathrm{~mm}$ panels respectively. A shuttle system could be applied to perform the heat-setting separately while the next preform is being deposited.

- Preheating time before final press moulding was established to be $200 \mathrm{~s}$ for $3 \mathrm{~mm}$ thick samples heated to $200^{\circ} \mathrm{C}$ using an IR oven. A smaller cycle time of for example $30 \mathrm{~s}$, required for high production volumes, could be reached by conventional means using a continuous multi-stage oven.

- Time at pressure was $30 \mathrm{~s}$ which gave low final void contents when using a pressure of 30 bar and rapid closure.

The main processing steps are hence typically in the $30 \mathrm{~s}$ range or below, making it possible to apply the TP-P4 process for high production volume applications. The only step which was time-limiting for the process was the isothermal consolidation, which could be established using a continuous press process, nevertheless at a high investment cost. Therefore a future paper will examine different preconsolidation options in more detail.

Final mechanical properties were compared with competing material technologies to examine the TP-P4 performance. The comparison showed that TP-P4 has higher mechanical properties than $40 \mathrm{wt} . \%$ GMT at both $20^{\circ} \mathrm{C}$ and $80^{\circ} \mathrm{C}$ and equivalent properties to 40 wt.\% GMTex, also at both temperatures. Nevertheless TP-P4 has slightly lower properties than 60 wt. $\%$ GMTex and Twintex in general at $20^{\circ} \mathrm{C}$, a difference which increased at $80^{\circ} \mathrm{C}$. As a whole the TP-P4 managed to deliver good mechanical properties for a planar-random material. 
With overall fast processing and delivering useful mechanical properties, the TP-P4 preforming and press forming process possess good behaviour for future high volume applications. Having examined the use of non-isothermal stamp forming of TP-P4 preforms, the next natural step will be taken in a future paper on the flow-moulding behaviour of the TP-P4 material.

Acknowledgements This work was supported by the EPFL and the Automotive Composites Consortium; comprising Daimler Chrysler, Ford Motor Company General Motors and the US department of energy and US Council for Automotive research (USCAR). The authors wish to thank J. Carron, D. May, L. Kämpfer and G. Pasche from the EPFL, J. Dahl, G. Smith, M. DeBolt, R. Cooper and D. Houston from Ford Motor Co., S.A. Iobst from General Motors and K.D. Yarborough and R.D. Lomax from Oak Ridge National lab as well as C. Ducret from Owens Corning. The authors would also like to acknowledge the National Composites Center for aid with the processing.

\section{References}

1. Chavka, N.G., Dahl, J.S.: P4: glass fiber preforming technology for automotive applications. Proc. of the SAMPE US Symp. and Exhib. 1999. Long Beach, USA

2. Brandt, M.R., Reeve, S.R.: Directed fiber preform case studies. Proc. of the Compos. Conv. and Trade Show. 2001. Tampa, USA

3. Automotive Composites Consortium, Developing Structural Composites for Large Automotive Parts, in Advanced Technology Program Status Report. 2004, Natl. Inst. of Stand. and Technol

4. Sherman, L.M.: SRIM: Material, Machine \& Process Innovations Give Birth to SRIM Truck Box. http:// www.ptonline.com/articles/200203cu2.html. Accessed 5 March 2008

5. Corum, J.M., Battiste, R.L., Ruggles, M.B., Ren, W.: Durability-based design criteria for a choppedglass-fiber automotive structural composite. Compos. Sci. Technol. 61(8), 1083-1095 (2001). doi:10.1016/S0266-3538(00)00242-6

6. Warrior, N.A., Harper, L., Turner, T., Schubel, P., Rudd, C., Kendall, K.: Affordable lightweight body structures (ALBOS). Proc. of the JSAE Annu. Congr. 2004. Yokohama, Japan

7. Harper, L., Turner, T., Warrior, N., Rudd, C.: Low cost carbon fibre-based automotive body panel systems. Proc. of the 27th SAMPE Eur. Conf. 2006. Paris, France

8. Reeve, S., Robinson, W., Cordell, T., Rondeau, R.: Carbon fiber evaluation for directed fiber preforms. Proc. of the 46th Int. SAMPE Symp. and Exhib. 2001

9. Schut, J.H.: Composites new rapid molding technologies and unusual reinforcements at Paris JEC Show. Plast. Technol. Online 2005 http://www.ptonline.com/articles/200506fa2.html. Accessed 5 March 2008

10. Kendall, K., Johnson, C.: Composites applications for the Aston Martin DB9. 2004 http://www.atl-uk. com/documents/CompositeApplicsDB9.pdf. Accessed 5 March 2008

11. Symosko, G.: High density structural RIM composites for large part applications. Proc. of the Compos. Conv. and Trade Show. 2003. California, USA

12. Iobst, S.A., Mao, C.H., Denton, D.L.: Optimization of the SRIM process for the ACC Composite Pickup Truck Box. Proc. of the SAMPE, Midwest Adv. Mater. and Process. Conf. 2000. Dearborn, USA

13. Svensson, N., Shishoo, R., Gilchrist, M.: Manufacturing of thermoplastic composites from commingled yarns - a review. J. Thermoplast. Compos. Mater. 11(1), 22-56 (1998)

14. Ye, L., Friedrich, K., Kästel, J.: Consolidation of GF/PP Commingled yarn composites. Appl. Compos. Mater. 1(6), 415-429 (1994). doi:10.1007/BF00706502

15. Jander, M.: P4, Owens Corning, internal presentation

16. Fabrication of a thermoplastic car bonnet in only 4 minutes. 2006, http://www.netcomposites.co.uk/news. asp?3967. Accessed 5 Feb. 2008

17. Wolfrath, J., Michaud, V., Månson, J.-A.E.: Graded glass mat-reinforced polypropylene. Polym. Compos. 26(3), 361-369 (2005)

18. Wolfrath, J., Michaud, V., Månson, J.-A.E.: Deconsolidation in thermoplastic composites: influence on the initial fibre/matrix architecture. Compos. Sci. Technol. 65, 1601-1608 (2005). doi:10.1016/j. compscitech.2005.02.001

19. Wolfrath, J., Michaud, V., Månson, J.-A.E.: Deconsolidation in thermoplastic composites: analysis of the mechanisms. Compos. Part A Appl. Sci. Manuf. 36, 1608-1616 (2005). doi:10.1016/j.composi tesa.2005.04.001 
20. Herper, L.T., Turner, T.A., Warrior, N.A., Rudd, C.D.: Characterisation of random carbon fibre composites from a direct fibre preforming process: the effect of tow filamentisation. Compos. Part A Appl. Sci. Manuf. 38, 755-770 (2007). doi:10.1016/j.compositesa.2006.09.008

21. Wakeman, M.D., Blanchard, P., Månson, J.-A.E.: Void evolution during stamp-forming of thermoplastic composites. Proc. of ICCM 15, 2005, Durban, South Africa

22. Cox, H.L.: The elasticity and strength of paper and other fibrous materials. Br. J. Appl. Phys. 3, 72-79 (1952)

23. Hull, D., Clyne, T.W.: An introduction to composite materials, 2nd edn. Cambridge University Press, Cambridge (1996)

24. O'Rourke, J.M., Bushby, R.R., Scott, V.D.: Evaluation of Al-Cu-Mg-Ag alloys containing discontinuous alumina fibres: II. Mechanical behaviour. Compos. Sci. Technol. 56, 1071-1077 (1996). doi:10.1016/0266-3538(96)00067-X

25. Cayron, C.: TEM study of interfacial reactions and precipitation mechanisms in $\mathrm{Al}_{2} \mathrm{O}_{3}$ short fibres or $\mathrm{SiC}$ particles reinforced $\mathrm{Al}-4 \mathrm{Cu}-1 \mathrm{Mg}-0.5 \mathrm{Ag}$ squeeze-cast composites, Thesis, École Polytechnique Fédérale de Lausanne, 2000

26. Törnqvist, R.: Tailored rheological and mechanical properties of fibre mat reinforced thermoplastics, Thesis, École Polytechnique Fédérale de Lausanne, 2000

27. Servais, C., Michaud, V., Månson, J.-A.E.: The packing stress of impregnated fiber mats. Polym. Compos. 22(2), 298-311 (2001) 